\title{
Recorregut de recerca geològica i mineralògica pel País de Fois I Foix (França): des de Montgailhard a les grottes de Lombribes i a les mines de Trimouns
}

Josep Maria Mata-Perelló

Joaquim Sanz Balagué
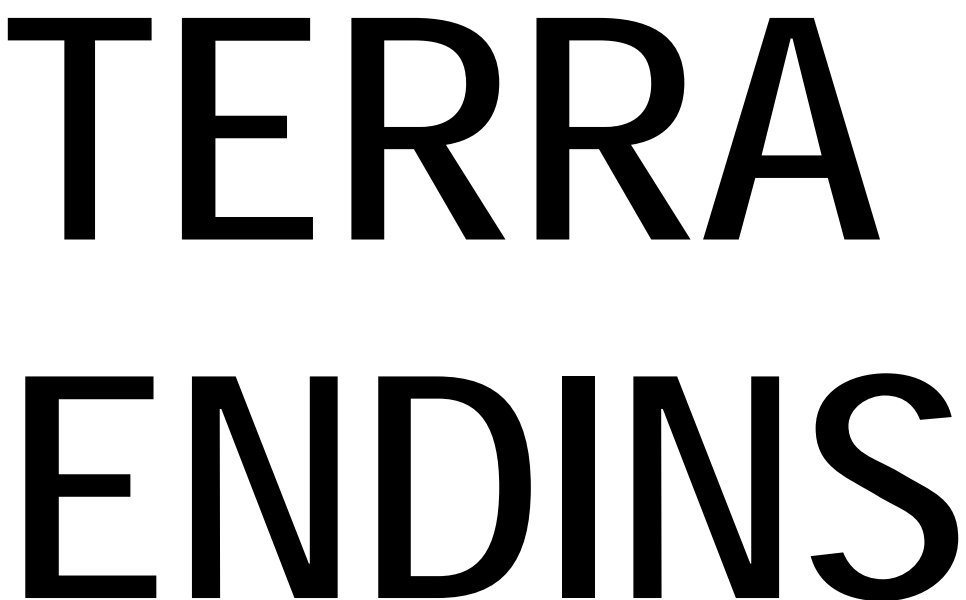

\section{REVISTA DE GEOLOGIA}

n. 1

MARÇ 2015 


\title{
RECORREGUT DE RECERCA GEOLÒGICA I MINERALÒGICA PEL PAIS DE FOIS I FOIX (FRANÇA): DES DE MONTGAILHARD A LES GROTTES DE LOMBRIBES I A LES MINES DE TRIMOUNS
}

\author{
Josep Maria Mata-Perelló \\ Museu de geologia Valentí Masachs, Escola Politècnica Superior d'Enginyeria de Manresa \\ (EPSEM), Universitat Politècnica de Catalunya · BarcelonaTech (UPC), 08272 Manresa, Spain
}

\author{
Joaquim Sanz Balagué \\ Departament d'Enginyeria Minera i Recursos Naturals (EMRN), Escola Politècnica Superior \\ d'Enginyeria de Manresa (EPSEM), Universitat Politècnica de Catalunya . BarcelonaTech \\ (UPC), 08272 Manresa, Spain
}

Paraules clau: Patrimoni geològic i miner; Mines de ferro; l'Ariège; materials neògens; Morfologia glacial

\begin{abstract}
Resum
Recorregut realitzat el 9 de juliol del 2013. El recorregut del present itinerari, es desenvoluparà íntegrament pel Sistema Pirinenc; distribuint-se tant per la denominada Zona Nord - Pirinenca com per la Zona Axial del Sistema Pirinenc. Així, el recorregut començarà dintre de la primera unitat, (dintre de l'antigament anomenat Prepirineu Septentrional), per la qual es circularà entre Montgailhard i les immediacions de Cabannes/les Cabanes. En aquest tram, es tallaran fonamentalment materials mesozoics, del Triàsic, del Juràssic i del Cretàcic; tot i que aquests darrers seran els que predominaran per tot arreu, al llarg del recorregut.
\end{abstract}

Posteriorment, el recorregut circularà pels anomenats Apilaments Antiformes de la Zona Axial Pirinenca, i més concretament dintre de l'anomenat Massís dels Tres Senhors, fent-se el recorregut per aquesta unitat entre Cabannes / les Cabanes, Luzenac / Lusenac i les Mines de Trimouns. En aquest recorregut es tallaran materials paleozoics del Cambro - Ordovicià, Silurià, Devonià i Carbonífer, fonamentalment.

Així el recorregut de l'itinerari s'iniciarà per les immediacions de la població de Montgailhard, des d'on es dirigirà després cap a Cabannes / les Cabanes i Lusenac / Luzenac. Per tal d'anar després cap a les Mines de Trimouns, per on finalitzarà.

Per d'altra banda, la totalitat del recorregut es realitzarà pel País de Fois / Foix (és a dir, pel Departament de I'Ariège) per on es realitzarà la totalitat del recorregut, recorrent la vall del riu del mateix nom i algunes de les valls dels seus afluents. 


\section{Objectius fonamentals}

A través d'aquest itinerari geològico-mineralògic, s'intentaran d'aconseguir els següents objectius, acord amb el sentit de la marxa del recorregut.

1.- Estudi i observació de la Zona Nord - Pirinenca (corresponent als antigament denominats Prepirineus Septentrionals) per la qual es circularà fonamentalment a la primera meitat del recorregut, entre les poblacions de Montgailhard i les Cabannes / les Cabanes.

2.- Observació, dels materials mesozoics (fonamentalment del Cretàcic), que constitueixen aquesta Zona Nord - Pirinenca, segons els indrets del recorregut, tot i que predominen sempre els darrers, en aquest itinerari.

3.- Observació dels Apilaments Antiformes de la Zona Axial Pirinenca;. Aquesta zona es tallarà a la part final del recorregut, entre les Cabannes / les Cabanes, Lusenac / Luzenac i les Mines de Trimouns.

4.- Observació com dels materials paleozoics que constitueixen la Zona dels Apilaments Antiformes de la Zona Axial Pirinenca. Aquests materials paleozoics pertanyen i fonamentalment pertanyen al Cambro-Ordovicià, a l'Ordovicià, al Silurià, al Devonià i al Carbonífer.

5.- Estudi de les relacions entre les dues unitats geològiques esmentades: entre la Zona Axial Pirinenca i la denominada Zona Nord - Pirinenca.

6.- Estudi de diverses mineralitzacions situades al llarg del recorregut de l'itinerari, com les mineralitzacions associades a skarn, de Lusenac / Luzenac, relacionada amb metasomatismes de contacte, respectivament, entre els materials del Cambro-Ordovicià.

7.- Estudi i observació de les explotacions relacionades amb els afloraments de les mineralitzacions acabades d'esmentar.

8.- Observació dels impactes mediambientals, produïts per les mineralitzacions anteriors; així com de les restauracions dutes a terme, si s'han realitzat.

9.- Observació dels diferents indrets relacionats amb el patrimoni geològic, que anirem trobant al llarg del recorregut del present recorregut. Entre aquests cal fer esment dels relacionats amb la Morfologia Glacial, que veurem per les immediacions de Trimouns (entre altres indrets) i amb la Morfologia Kàrstica, que veurem a la Grotte de Lombrives, entre altres indrets del recorregut.

10.- Observació dels diferents indrets relacionats amb el patrimoni miner, que anirem trobant al llarg del recorregut del present recorregut. Entre aquests cal fer esment del relacionat amb Forge de Montgailhard, entre altres indrets del recorregut.

\section{Antecedents}

En relació amb el recorregut del present itinerari, tot i que no coneixem l'existència de cap altre que segueixi aquest mateix recorregut, tret de vells itineraris nostres, els quals coincideixen en part amb el que ara presentem: Mata-Perelló (2006, 2009, 2010 i 2011). Tot i així, en aquest sentit, el darrers i aquest són els primers que discorren per molts dels indrets.

Per d'altra banda, farem esment de diversos treballs, de caràcter geològic general i regional, com són els següents: Guimerà et altri (1992), i Riba et altri (1976). També farem esment del publicat pel SGC (1990); així com de dos treballs de caràcter regional com són els publicats pel 
BRGM (1979a, 1970b i 1970c). Pel que fa a les mineralitzacions, farem esment dels treballs de: Fortune et altri (1980) i Grignac, Ch (1994).

Tots aquests treballs, i d'altres, figuraran degudament relacionats per ordre alfabètic, i per data de publicació, dintre de l'apartat d'aquest treball dedicat a les referències bibliogràfiques, al qual ens adrecem.

\section{Recorregut de l'itinerari}

El recorregut d'aquest itinerari el començarem a la població de Montgailhard (situada I'antiga carretera nacional $\mathrm{N}-20$ ), per on es realitzarà la primera aturada. Després, el recorregut es dirigirà cap el Nord, seguint la carretera N - 20. Així, s'arribarà a Tarascon.

Després, convindrà continuar cap el Nord, cap a Ornalac. Des d'aquí, s'anirà, seguint la mateixa carretera, cap a les immediacions de Sinsat. Poc després d'arribar a aquesta població (quasi a l'entrada) es farà una visita a la Grotte de Lombrives, per on es farà una nova aturada.

Després, el recorregut continuarà cap el Nord, cap als pobles de Les Cabannes / les Cabanes i de Lusenac / Luzenac, recorrent sempre la carretera nacional $N-20$, remuntant el riu Arieja.

Poc després d'aquesta darrera població, ens caldrà anar cap a llevant, per tal d'arribar a les Mines de Trimouns, per on finalitzarà el recorregut de l'itinerari, tot fent-se la darrera aturada del mateix.

\section{Advertiments previs}

Com en altres recorreguts de recerca geològica i mineralògica ..., si es disposa del temps suficient, poden efectuar-se passant per totes les parades i filloles. En cas contrari, recomanem prescindir de les anomenades parades - condicionals.

També recomanem que es demani informació sobre l'estat dels diferents trams de les pistes forestals, per les quals s'ha de circular, en el recorregut de l'itinerari, per tal d'evitar problemes secundàries. En aquesta ocasió, el recorregut transitarà per un tram dificultós: el que ens conduirà des del Port de Pimorent cap a la mina de ferro del mateix nom. aquesta ocasió, aquest recorregut el farem a peu.

Per d'altra banda, i a l'igual que en altres recorreguts semblants, recomanem tenir el màxim de cura i de respecte, entorn de la Natura que ens rodeja.

\section{Descripció de l'itinerari}

Com de costum, estructurarem el recorregut de l'itinerari en una sèrie de parades ( 0 d'estacions), que tot seguit anirem veient. en cadascuna d'aquestes aturades farem un breu comentari (geològic o mineralògic, segons s'escaigui), alhora que indicarem la forma d'arribarhi en cada cas, tot partint de la parada anterior. Igualment indicarem els trets geològics més representatius, corresponents al trànsit d'una aturada cap a la següent.

Per d'altra banda, en cada cas indicarem, entre parèntesi, el full topogràfic (a escala 1:50.000) on es troba l'aturada. En aquest cas utilitzarem els fulls de I'IGN (Institut Geographique National, de França), que seran els següents fulls: 2147 (o de Foix), 2148 (o de Vicdessos) i 2248 (o d'Ax-les-Termes). La totalitat de les aturades, es realitzarà dintre dels fulls acabats 
d’esmentar. Així doncs, la relació ordenada de les aturades que composen aquest recorregut, és la següent:

\subsection{Parada 1. Farga de Montgailhard, (terme de Montgailhard, País de Fois, Ariège). (Full 2147).}

El recorregut d'aquest itinerari, el començarem prop de la localitat de Montgaillard / Montgailhard, a uns $15 \mathrm{Km}$ de Tarascon, aigües aval del riu Arieja i molt prop de la capital, la població de Fois / Foix. Així, el recorregut l'iniciarem a tocar de l' antiga carretera nacional N 20, a uns $5 \mathrm{Km}$ de Foix i a $1 \mathrm{Km}$ de Montgailhard.

En aquest indret hi ha la reconstrucció d'una Farga Catalana (Forge Catalana), que es troba actualment en funcionament, com a mostra turística. Al costat d'aquest establiment preindustrial hi ha la recreació de tot un poblat metal-lúrgic. Creiem que és interessant de veure-la. (fotografia 1 ).

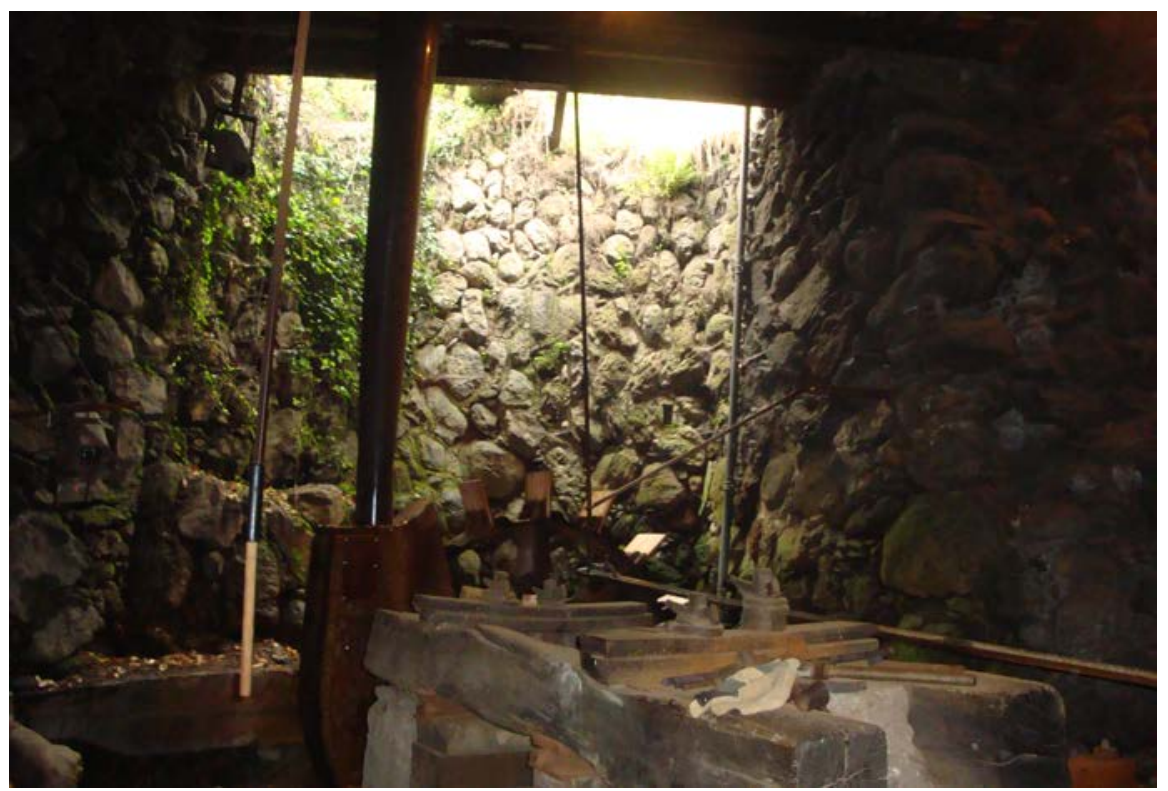

FOTOGRAFIA 1. Un aspecte de la Forge de Montgailhard

Aquest indret es troba situat a la vora del riu Arieja, entre afloraments dels materials de I'Holocé i del Pleistocè. Al mateix temps es localitza dintre de la denominada Zona Nord Pirinenca, on ens trobem de nou. Aquests afloraments pertanyen en bona part al Cretàcic i tenen caràcter carbonatat.

\subsection{Parada 2. Grotte de Lombrives, (terme d'Ussat - les Bains, País de Fois, Ariège). (Full 2148 de I’IGN).}

Des de la parada anterior caldrà continuar cap a Tarascon, seguint sempre per la carretera N 20. Després de sobrepassar la població anterior, ens caldrà arribar a les immediacions d'Ussat - les - Bains. En aquest recorregut, hem passat per diverses per les immediacions de diverses poblacions com: Mercus, Bompas i Tarascon - sur -Ariège. Quasi a l'entrada de la població d'Ussat - les - Bains, ens caldrà fer una nova aturada, per tal d'anar cap a la Grotte de 
Lombrives, situada a l'esquerra de la carretera, segons el nostre sentit de la marxa. Així, des de la parada anterior, haurem realitzat un recorregut proper als $22 \mathrm{Km}$.

Aquest recorregut I'haurem efectuat entre els afloraments (fonamentalment carbonatats del Cretàcic), que pertanyen a la Zona Nord - Pirinenca, on estem ara situats des de les immediacions de la parada anterior, del principi del recorregut.

En aquest indret hi ha una de les coves més importants del País de Fois, la Grotte de Lombrives. Es tracta, possiblement d'una de les coves més grans dels Pirineus, situada entre els afloraments carbonatats del Cretàcic, dintre de la Zona Nord - Pirinenca. (fotografies 2 i 3 ).
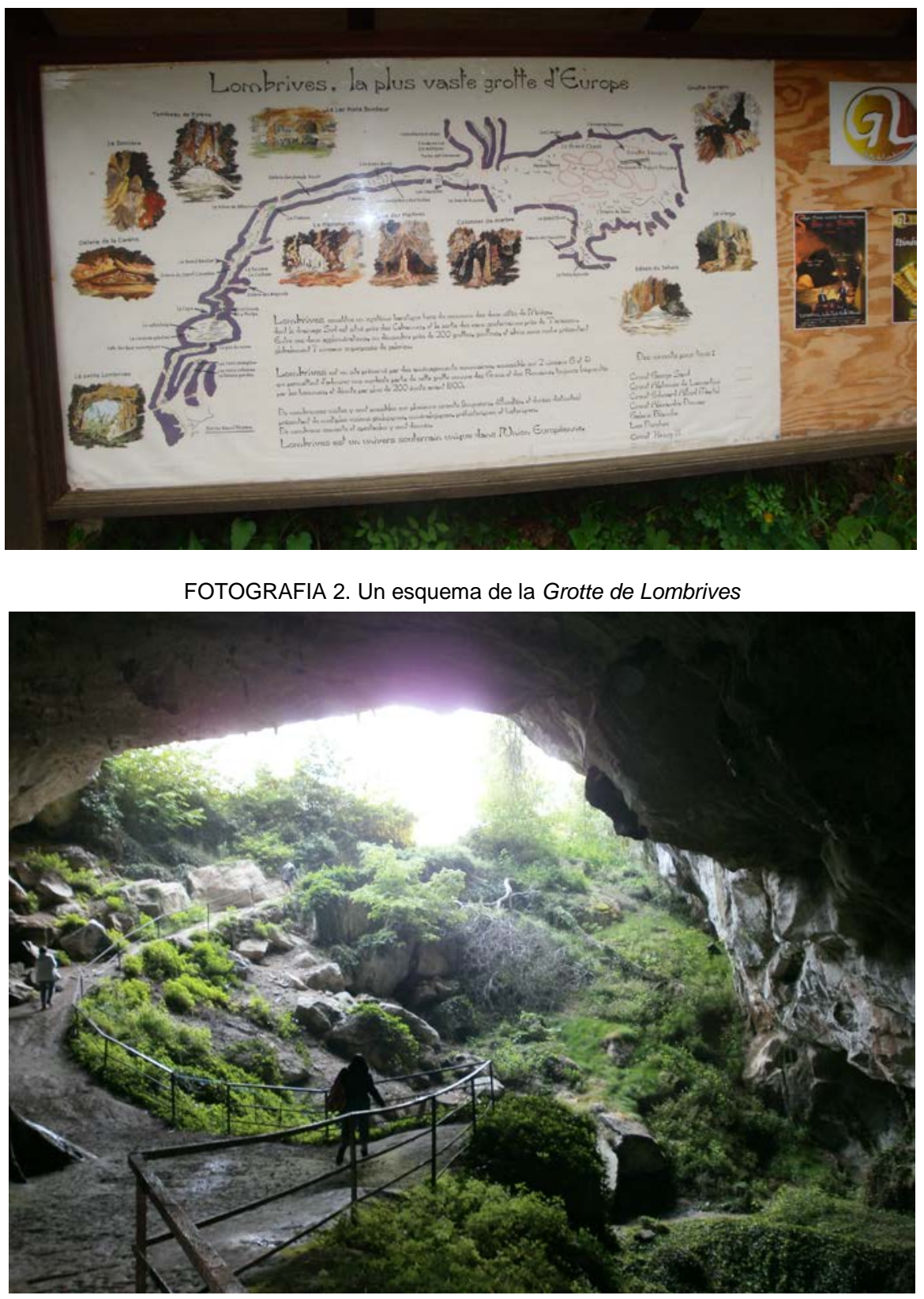

FOTOGRAFIA 3. Entrada a la Grotte de Lombrives 
Aquesta cova, forma part del sistema kàrstic de la cova de Niaux /Niaus, que te una gran importància internacional, en funció de l'art rupestre de les seves pintures. Malgrat aquesta proximitat, en aquesta cova de Lombrives no hi ha evidencies rupestres, que nosaltres coneixem.

Per d'altra banda, des de la Cova de Lombrives, mirant cap a l'altra banda del riu, és fàcil veure altres coves

\subsection{Parada 3. Immediacions de les Cabannes I les Cabanes, (terme de les Cabannes / les Cabanes, País de Fois, Ariège). (Full 2247 de l'IGN).}

Des de la parada anterior caldrà retornar a la carretera $\mathrm{N}-20$, per tal de continuar cap el Nord, ascendent per la vall del riu Arieja. Així, anirem passant per diverses poblacions situades a la vora de la carretera, com: Sinsat i les Cabannes / les Cabanes. Poc després de sobrepassar aquesta darrera, farem una nova aturada. Així, des de la parada anterior, haurem efectuat un recorregut proper al $10 \mathrm{Km}$, per tal d'arribar fins aquí.

Tot aquest recorregut, l'haurem efectuat entre els afloraments mesozoics de la denominada Zona Septentrional Pirinenca o Zona Nord - Pirinenca (que ve a coincidir amb I'antigament denominada com Prepirineu Septentrional). Cal dir que aquests afloraments mesozoics que hem anat trobant al llarg d'aquest tram, son eminentment carbonatats

Així, des d'aquest indret es fan ben palesos els relleus carbonatats cretàcics, que formen part de la denominada. Concretament, des d'aquest indret estem veien els relleus de le Quié, tot mirant cap el Nord d'on ara som. (fotografia 4).

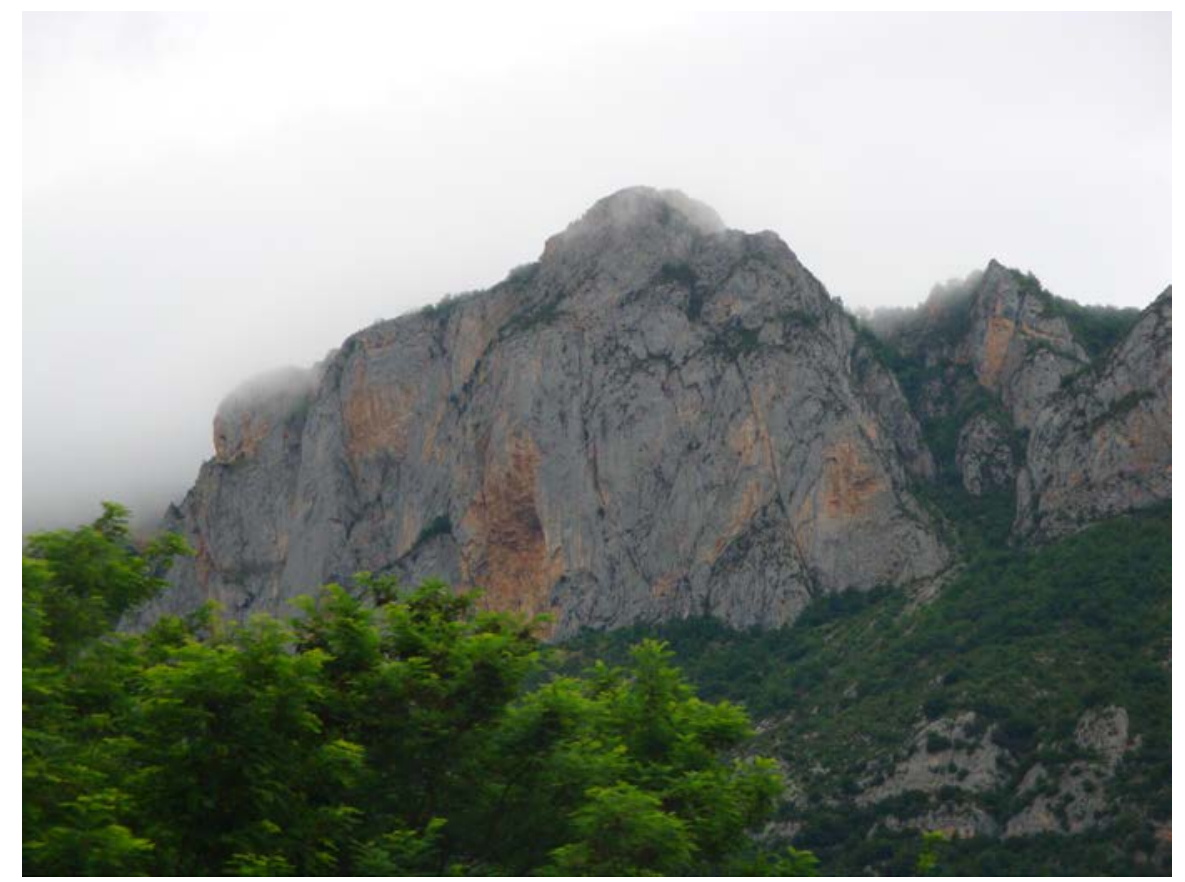

FOTOGRAFIA 4. Relleus de le Quié. Zona Nord - Pirinenca o Pirineus Septentrionals 


\subsection{Parada 4 - condicional. Fàbrica de talc, (terme de Lusenac / Luzenac, País de Sault, Ariège), (Fulls 2148 de l'IGN).}

Després de realitzar la parada anterior, cal efectuar un breu recorregut per la carretera nacional $\mathrm{N}-20$, tot anant cap el Nord, remuntant sempre el riu Arieja. Així, després de passar pels voltants de Albiès i de Lassaur, arribarem ben aviat a Lusenac / Luzenac. Quasi a la seva sortida septentrional, podem fer una nova aturada, si s'escau, a uns $14^{\prime} 5 \mathrm{Km}$ de la parada darrerament efectuada.

En aquest recorregut, hem deixat enrere la Zona Nord - Pirinenca i hem entrat a la Zona Axial (concretament a la Zona dels Apilaments Antiformes de la Zona Axial Pirinenca), on ara estem situats. Així, per arreu, es fan palesos els afloraments dels materials paleozoics, fonamentalment els materials del Devonià i els de l'Ordovicià.

En aquest indret hi ha la Fàbrica de Talc de Luzenac (la coneguda Usine de Luzenac). Així, aquí arriba el talc explotat a les Mines de Trimouns, que veurem a la propera aturada d'aquest itinerari.

\subsection{Parada 5. Pedreres de talc de Trimouns (terme de Luzenac I Lusenac, País de Sault, Ariège), (Fulls 2148 i 2248).}

Després de fer l'aturada anterior, ens caldrà acabar de travessar la població de Luzenac I Lusenac, per tal d'agafar un trencall que surt per la dreta (la carretera departamental D-2), que es dirigeix cap a Unac. Abans d'arribar a Savenac, caldrà agafar un altre trencall, ara per I'esquerra (la carretera D-20), per tal d'anar cap a Bestiac i cap a Lordat. Finalment, des d'aquest darrer poble, cal agafar un darrer trencall (per la dreta), que s'adreça directament cap a les Pedreres de Talc de Trimouns. Així, haurem fet un recorregut d'uns $4 \mathrm{Km}$, des de Luzenac i uns 15 aproximadament, des de la parada anterior.

La totalitat d'aquest recorregut s'haurà fet per la Zona dels Apilaments Antiformes de la Zona Axial Pirinenca, on ara ens trobem situats. Així en els darrers trams es van tallant freqüents afloraments de materials granítics, així com nivells esquistosos i també carbonatats del Cambro-Ordovicià.

Les explotacions es realitzen a càrrec de l'empresa Talcs de Luzenac, i per accedir-hi, cal tenir la corresponent autorització (Tf. 33-5-61.02.04.06). Aquestes explotacions es realitzen a cel obert, entre els mesos de maig i d'octubre, donades les condicions climatològiques adverses al llarg hivern. Per aquesta circumstàncies, cal informar-se adequadament de l'estat del temps, com a conseqüència de l'altitud del lloc de les explotacions.

Les mineralitzacions es troben situades sobre uns afloraments de calcàries dolomítiques que pertanyen a l'Ordovicià (i més concretament al Caradoc). Aquests nivells han sofert un metasomatisme, amb fenòmens d'hidrosilificació. Molt probablement els aportaments de sílice procedeixen dels gneis propers. Els nivells de calcàries dolomítiques pertanyen als Apilaments Antiformes de la Zona Axial Pirinenca, i es troben a l'extrem oriental del Massís de Sant Bertomiu / Saint Barthélémy.

Entre els minerals presents, cal fer un especial esment del talc, que fins i tot pot aparèixer ben cristal-litzat. També es troben, entre altres: pirita (ben cristal-litzada, normalment), calcita, clorita i quars. Com es natural, de tots ells, solament el primer és el mineral beneficiat a les explotacions. 


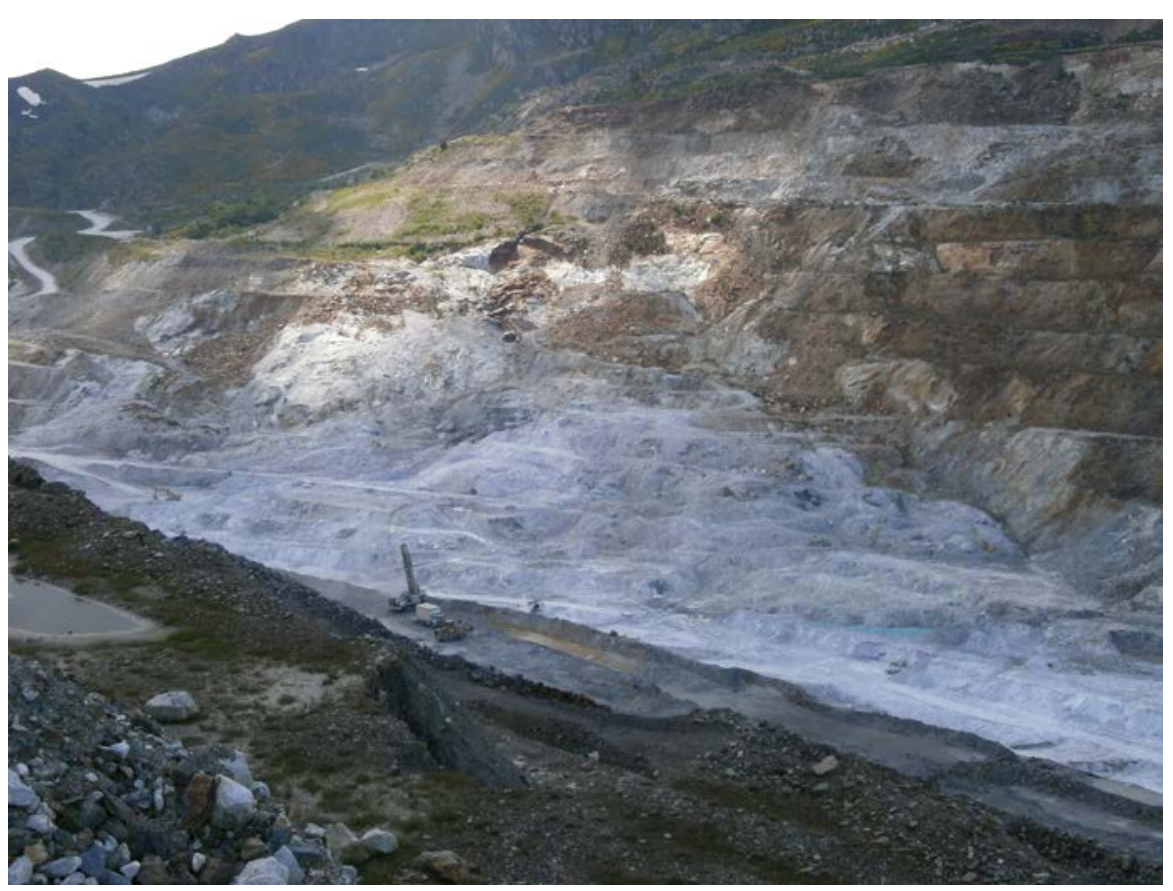

FOTOGRAFIA 5. Un aspecte de l'explotació dels talcs

Aquestes explotacions es realitzen a "cel obert", amb una interessant mecanització, que cal visitar i observar amb cura, donada la seva importància; ja que són les explotacions més importants, de totes les situades als Pirineus, i realitzades a "cel obert". (fotografies 5 i 6 ).

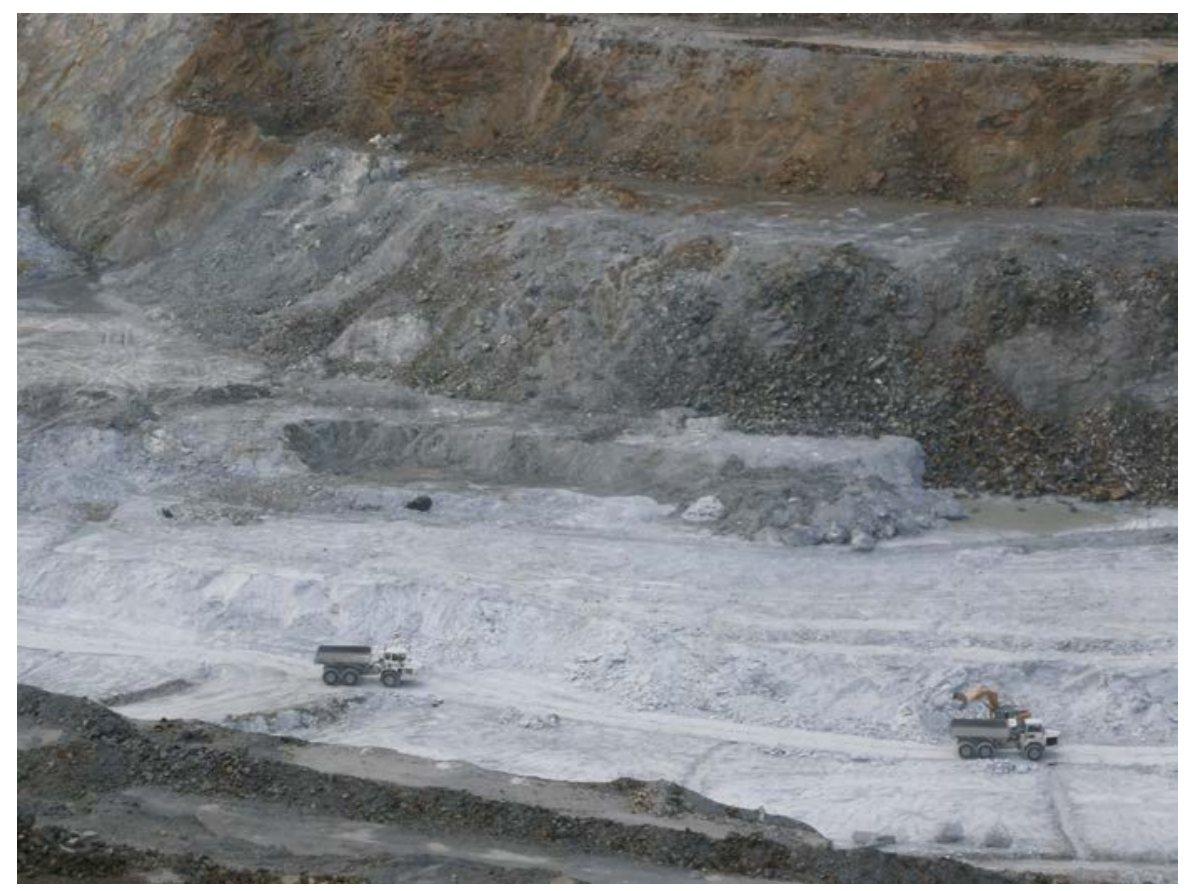

FOTOGRAFIA 6. Un altre aspecte de l'explotació dels talcs 
Cal considerar que aquesta pedrera, es considera que és l'explotació de talcs a cel obert, més gran del món.

Finalment, cal dir que de d'aquest indret, mirant cap a ponent i cap el Nord, es pot gaudir d'una bona observació de les valls de I'Arieja; i en particular de la seva espectacular morfologia glacial.

El recorregut de l'itinerari finalitza en aquest lloc

\section{Bibliografia emprada}

BRGM (1970a).- Carte géologique de France a 1/50.000. Fuille d’Ax - les- Termes. Direcction du Service Geéologique et des Labotatoires. Orleans - Source

BRGM (1970a).- Carte géologique de France a 1/50.000. Fontargente. Direcction du Service Geéologique et des Labotatoires. Orleans - Source

BRGM (1970a).- Carte géologique de France a 1/50.000. Mont-Louis. Direcction du Service Geéologique et des Labotatoires. Orleans - Source

FORTUNE, JP, GAVOILLE, B. et THIEBAUT, J. (1980).- Le gisement de talc de Trimouns (pres de luzenac - Ariège). Gisements Français - Fascicule E10 - 26éme Congrès Géologique international. Paris.

GRIGNAC, Ch (1994).- La carrière de Trimouns de TALC DE LUZENAC. Mines et Carrières / Industrie Minérale. Août / Septembre 1994. Paris.

GUIMERÀ, J. et altri. (1992).- Geologia (II), Història Natural dels Països Catalans, Vol. 2, 547 pag. Enciclopèdia Catalana, S.A., Barcelona

MATA-PERELLÓ, J.M. (2003 - 2006).- Apunts de camp sobre les mineralitzacions del Capcir, del Departament de l'Arieja i del Departament de l'Aude. Inèdit. Manresa

MATA-PERELLÓ, J.M. (2009).- Recorregut de recerca geològica i mineralògica pels departaments de l'Aude (País d'Axat) i de l'Arieja (País de Sauth i País de Foish): des d'Axat a Belvianes, Marsa, Joucou, Lusenac i Rancié. Inèdit, 10 pag. Manresa

MATA-PERELLÓ, J.M. (2010).- Recorregut de recerca geològica i mineralògica pels Departaments dels Pirineus Orientals (Fenolheda), Aude (Pais d'Axat) i d'Arieja (Pais de Sauth i Pais de Foish): des de Sant Pau de Fenolhet a Caudies de Fenolheda, Axat, Belvianes, Marsa, Joucou, Lusenac i Rancie. Inèdit. 10 pag. Manresa

RIBA ARDERIU, O. Et altri. (1976).- Geografía Física dels Països Catalans. Edit Ketres, 210 pàgines. Barcelona

SGC (1990).- Mapa Geològic de Catalunya a escala 1:250.000, Servei Geològic de Catalunya (Inst. Cartògraf. de Catalunya). Barcelona 